\title{
PROPORTION AND RISK FACTORS OF DIFFICULT INTUBATION ASSOCIATED WITH THYROID SWELLING
}

\author{
Sheela Prabhakaran'1, Manu Sudevan² \\ ${ }^{1}$ Additional Professor, Department of Anaesthesiology, Government Medical College, Kozhikode. \\ ${ }^{2}$ Consultant Anaesthesiologist, S. K. Hospital, Thiruvananthapuram.
}

ABSTRACT
BACKGROUND AND AIM
Difficult intubation in a patient with thyroid swelling is associated with risk factors related to the patient and the thyroid
swelling. The risk factors related to thyroid swelling causing difficult intubation has rarely been studied in our population and
published studies are relatively small. By knowing the risk factors, Anaesthesiologist can take adequate measures to face such
scenario and can reduce the mortality and morbidity associated with difficult intubation. The aim of this study is to determine the
proportion and risk factors of difficult intubation associated with thyroid swelling.

\section{METHODS}

After obtaining Institutional and Ethical approval, 200 consenting patients scheduled for elective thyroidectomy were enrolled in this prospective observational study. Patients with history of difficult intubation and obvious airway anomaly were excluded. All patients are assessed for thyroid related and patient related variables by the investigator. After inducing anaesthesia, difficulty in intubation was assessed using Intubation Difficulty Scale (IDS) and IDS score was calculated for each patient by the anaesthesiologist in charge of the operation table. Patients are grouped as either not having or having difficulty in intubation. A univariate followed by a multivariate analysis was done to determine the potential and independent risk factors of difficult intubation associated with thyroid swelling.

\section{RESULTS}

Study shows a higher incidence of Thyroid disorders in female population (90.5\%). In the study population, 39.5\% have difficulty in intubation (IDS $>0$ ), of which $7 \%$ had severe intubation difficulty (IDS $>5$ ). Variables conferring increased odds of difficulty in intubation include male gender (OR 16.3, CI 3.6-72), thyroid swelling with tracheal deviation (OR 8.8, CI 3.4-22.8), thyroid swelling with compressive symptoms like dyspnoea, dysphagia or hoarseness of voice (OR 9.0, CI 2.8-35.5), swelling with duration more than 5 yrs. (OR 4.8, CI 1.8-13) and multinodular goitre (OR 6.3, CI 3.3-12.2). Of these male gender, thyroid swelling with compressive symptoms and malignant thyroid swelling are the three independent risk factors associated with difficult intubation.

\section{CONCLUSION}

Our study shows that $60.5 \%$ of patients with thyroid swelling can be intubated easily in the first attempt itself even without an assistant. The rest of the patients need some or other forms of manipulations or assistance. Three variables male gender, carcinoma thyroid and thyroid swelling with compressive symptoms are the independent risk factors associated with difficult intubation.

\section{KEYWORDS}

Thyroid Swelling, Difficult Intubation, Risk Factors, Intubation Difficulty Scale.

HOW TO CITE THIS ARTICLE: Prabhakaran S, Sudevan M. Proportion and risk factors of difficult intubation associated with thyroid swelling. J. Evolution Med. Dent. Sci. 2016;5(67):4851-4855, DOI: 10.14260/jemds/2016/1103

\section{INTRODUCTION}

When a patient is scheduled for thyroid surgery, risk factors related to the patient as well as the thyroid swelling can lead to difficulty in intubation. Enlarged thyroid gland may cause tracheal deviation or compression or both, leading to difficult intubation.[1] But it has been observed that the size of the thyroid swelling alone is not the only determining factor for difficult intubation. Many other risk factors related to thyroid may cause difficult intubation. Patient's airway related factors associated with difficult intubation has been widely investigated in the general surgical population. ${ }^{[2-5]}$ However, the risk factors related to thyroid swelling causing difficult

Financial or Other, Competing Interest: None.

Submission 14-07-2016, Peer Review 06-08-2016,

Acceptance 13-08-2016, Published 22-08-2016.

Corresponding Author:

Dr. Sheela Prabhakaran,

Anjali, Thottumkara,

Mayyanad P.O., Kollam-691303.

E-mail: drsheelasheya@gmail.com

DOI: $10.14260 /$ jemds/2016/1103 intubation has rarely been studied in our population and published studies are relatively small.[6-8] If Anaesthesiologist knows the risk factors of difficult intubation associated with thyroid swelling, he can take necessary steps to face it and can avoid morbidity and even mortality associated with it. The aim of this study is to determine the proportion of difficult intubation in patients with thyroid swelling and also to find the thyroid related risk factors associated with difficult intubation.

\section{METHODS}

After obtaining Institutional and Ethical approval, consenting patients of either sex of all age groups and American Society of Anaesthesiologist (ASA) class 1 and 11, scheduled for elective thyroidectomy during the study period of one year were enrolled in this study until the sample size is achieved. Patients with history of difficult intubation and with obvious airway abnormalities were excluded from the study. For $95 \%$ confidence interval, $90 \%$ precision and $63 \%$ expected proportion the sample size calculated was 200 . 
All patients enrolled in the study underwent a thorough pre-anaesthesia check-up by the principal investigator. The following study variables were noted. The demographic variables include age, gender, height, weight and the ASA PS status. The thyroid related variables recorded included duration of thyroid swelling in months; neck circumference which is measured at the point of maximum thyroid enlargement perpendicular to the long axis of the neck, presence of compressive symptoms like dyspnoea, hoarseness or dysphagia, presence of tracheal deviation in $\mathrm{X}$ ray defined as deviation of upper part of trachea from the median line more than $1 \mathrm{~cm}$ when the clavicles are symmetric and the head is in neutral position in the radiograph of neck and chest, character of swelling which was noted as either a solitary nodule, multinodular goitre or as a cancerous swelling and whether the patient is on any thyroid related medication like hypo or hyperthyroid state.

The patient's airway related variables causing difficult intubation have been studied extensively elsewhere, but it cannot be excluded from the present study. Those variables are Mallampati class, Atlanto-occipital joint extension, Thyromental distance and Wilson score.

Mallampati classification. ${ }^{[9,10,11]}$ Patient is seated in front of the examiner so that the patient's oral cavity is at the examiner's eye level. Then ask the patient to open the mouth as widely as he can without protruding tongue or saying 'ah.'

\section{Depending on the Structures that are Visible in the Oral} Cavity, Patients are classified as follows:

Class I: Soft palate, tonsillar fauces, tonsillar pillars and uvula visualised.

Class II: Soft palate, tonsillar fauces and uvula visualised.

Class III: Soft palate and base of uvula visualised.

Class IV: Soft palate not visualised (Samson and Young Modification).

Intubation difficulty increases as patient comes underclass III or IV.

Atlanto-occipital joint extension.[4] This angle can be measured at the bedside by asking the patient to sit straight up with the head erect and the line of sight parallel to the ground. Then ask the patient to open mouth wide. In this position, the occlusal surfaces of the upper teeth are horizontal to the ground. On extending the atlanto-occipital joint, the angle created by moving the occlusal surfaces is estimated. Goniometer is used to estimate the angle more accurately. Reduction in extension is expressed in grades as Grade 1: >35, Grade II: $22^{\circ}-34^{\circ}$, Grade III: $12^{\circ}-21^{\circ}$, Grade IV: $<12^{\circ}$. Normal angle of extension is $35^{\circ}$ or more. There will be difficulty in intubation when the angle of extension becomes less.

Thyromental distance.[4,12,13] Distance from the mentum to the thyroid notch, while patient's neck is fully extended. Normal distance is $>6.5 \mathrm{~cm}$. Expect difficulty in intubation if the distance is $6.5-6.0$ and very difficult if the distance is $<6.0$ $\mathrm{cm}$.

Mouth opening.[5] The adequacy of mouth opening is assessed by measuring the inter-incisor distance. An interincisor distance of $3 \mathrm{~cm}$ provides sufficient space for intubation. This corresponds approximately to two fingerbreadths. The two finger-breadth test is performed by placing the examiner's second and third digits between the patient's central incisors. If they fit, there should be adequate space to perform laryngoscopy. If they do not fit, laryngoscopy may be difficult.

Wilson score.[3] A simplified predictive rule based on adverse risk factors can identify patients who may be difficult to intubate. Risk factors are body weight, head and neck movement, jaw movement based on inter-incisor gap and mandibular subluxation, receding mandible, buck teeth. Wilson score of 5 or more is taken to indicate a risk of difficult intubation.

On the pre-operative day, T. Alprazolam $0.25 \mathrm{mg}$, T. Pantoprazole $40 \mathrm{mg}$ with Domperidone $10 \mathrm{mg}$ are given at bed time for all patients and are repeated at $6.00 \mathrm{am}$ on the day of surgery. All patients received uniform technique of general anaesthesia as per the institutional protocol. After induction and confirming the adequacy of bag and mask ventilation succinylcholine $(2 \mathrm{mg} / \mathrm{kg})$ is given and ventilation with bag and mask is continued for 60 secs. Laryngoscopy was performed by the unassisted anaesthesiologist in charge of the operating table who has not less than 3 yrs. experience and laryngoscopic view is graded based on Cormack and Lehane grading. Patient is then intubated using appropriatesized cuffed oral endotracheal tube. In cases of difficulty experienced during laryngoscopy, Macintosh size ' 4 ' blade is used or external laryngeal pressure is applied or intubated with the help of a bougie. The difficulty in intubation was assessed using Intubation Difficulty Scale (IDS) by the attending anaesthesiologist and IDS score was calculated for each patient. The IDS (Intubation Difficulty Scale) is a function of seven factors that have been associated with difficult intubation. There are number of intubation attempts, additional operators needed, additional intubation techniques used, Cormack-Lehane grade during laryngoscopy, lifting force required to make laryngoscopy, application of external laryngeal pressure and position of vocal cords during laryngoscopy.

\section{Number of Intubation Attempts}

With every additional intubation attempt adding one point to the total score, one attempt was given zero point.

\section{Number of Additional Operators}

With each additional operator, add one point to the total score.

Number of Additional Intubation Techniques used (eg. Patient reposition, change of blade or tube change approach): With each modification, add one point to the score.

\section{Cormack-Lehane Grade during Laryngoscopy}

The Cormack and Lehane classification[14] on the basis of a study of obstetric patients is the original and most widely used classification of laryngeal view during direct laryngoscopy. Grade I-Visualisation of entire laryngeal aperture, Grade II-Visualisation of only posterior commissure of laryngeal aperture, Grade III-Visualisation of Epiglottis, Grade IV-Visualisation of just the soft palate, Grade III and IVIndicate difficult intubation. Patient will get a score equal to Cormack and Lehane grade minus 1 . So if the grade is 1 , score will be zero.

Lifting Force required to make Laryngoscopy: Normal lifting force gets no points. Increased force gets one point.

Application of External Laryngeal Pressure: If it is needed, one point is added to total score.

Position of Vocal Cords during Laryngoscopy: Zero point for the abducted position and one point for the adducted position. 
A total score of zero indicate easy intubation, 1-5 score indicate slightly difficult intubation, a score of $>5$ indicate moderate-to-major difficulty. In this study, IDS score more than zero was taken as having difficult intubation. An IDS score 0 means one can intubate the patient in the first attempt itself with appropriate sized ETT without any assistant's help, without external laryngeal manipulation and without undue pressure on the vallecula.

\section{Statistics}

Data was analysed using computer software "Statistical Package for Social Sciences" (SPSS) Ver-16 for windows. Patients are grouped as either not having (IDS $=0$ ) or having (IDS $>0$ ) difficult intubation. A case control analysis was done to determine the risk factors of difficult intubation associated with thyroid swelling. Univariate analysis was done to identify the potential thyroid related risk factors associated with difficult intubation. Multivariate analysis was done to identify the independent risk factors associated with difficult intubation.

\section{RESULTS}

\begin{tabular}{|c|c|c|}
\hline IDS Score & Frequency (Number) & Percentage (\%) \\
\hline 0 & 121 & 60.5 \\
\hline $1-5$ & 65 & 32.5 \\
\hline$>5$ & 14 & 7 \\
\hline Total & $\mathbf{2 0 0}$ & $\mathbf{1 0 0}$ \\
\hline \multicolumn{2}{|c|}{ Table 1: Distribution according to } \\
IDS (Intubation Difficulty Score)
\end{tabular}

In the study population, $39.5 \%$ have difficulty in intubation (IDS >0), of which $7 \%$ had severe intubation difficulty (IDS $>5$ ); $60.5 \%$ of the study population were intubated very easily.

\begin{tabular}{|c|c|c|c|c|}
\hline Gender & $\begin{array}{c}\text { Difficult } \\
\text { Intubation (IDS >0) }\end{array}$ & $\begin{array}{c}\text { No Difficulty } \\
\text { (IDS=0 ) }\end{array}$ & Odds Ratio (CI) & P value \\
\hline Male & $17(89.5 \%)$ & $2(10.5 \%)$ & \multirow{2}{*}{$16.3(3.6-72)$} & 0.001 \\
\hline Female & $62(34.3 \%)$ & $119(65.7 \%)$ & \\
\hline \multicolumn{2}{|r|}{ Table 2: Comparison of Two Groups by Gender } \\
\hline
\end{tabular}

Out of the 200 study population, 181 (90.5\%) constituted females and 19 (9.5\%) males showing the higher prevalence of thyroid disorders in females. Of the 79 patients with mildto-severe intubation difficulty, 17 were males and 62 females.
In males $89.5 \%$ showed intubation difficulty while only $34.3 \%$ in females, which was found to be statistically significant.

\begin{tabular}{|c|c|c|c|c|c|}
\hline \multicolumn{2}{|c|}{ Variables } & \multirow{2}{*}{$\begin{array}{c}\text { Difficult } \\
\text { Intubation (IDS>0) } \\
\text { Number (\%) }\end{array}$} & \multirow{2}{*}{$\begin{array}{c}\text { No } \\
\text { Difficulty (IDS=0) } \\
\text { Number (\%) }\end{array}$} & \multirow{3}{*}{$\begin{array}{c}\text { Odds } \\
\text { Ratio (CI) } \\
\\
0.7 \\
(0.2-1.8)\end{array}$} & \multirow{3}{*}{$\begin{array}{c}\text { P Value } \\
0.46\end{array}$} \\
\hline \multirow{2}{*}{ Mallampati Class } & I \& II & & & & \\
\hline & III \&IV & $9(47.4 \%)$ & $10(52.6 \%)$ & & \\
\hline \multirow{2}{*}{$\begin{array}{c}\text { Thyromental } \\
\text { Distance }\end{array}$} & $<6.5 \mathrm{~cm}$ & $2(66.7 \%)$ & $1(33.3 \%)$ & \multirow[b]{2}{*}{$\begin{array}{c}3.1 \\
(0.2-34)\end{array}$} & \multirow[b]{2}{*}{0.33} \\
\hline & $\geq 6.5 \mathrm{~cm}$ & $77(39.1 \%)$ & $120(60.9 \%)$ & & \\
\hline \multirow{2}{*}{$\begin{array}{l}\text { Atlanto-Axial } \\
\text { Extension }\end{array}$} & Grade 1 & $70(36.8 \%)$ & $120(63.2 \%)$ & \multirow[b]{2}{*}{$15.4(1.9-124)$} & \multirow[b]{2}{*}{0.001} \\
\hline & Grade11 & $9(90 \%)$ & $1(10 \%)$ & & \\
\hline \multirow{2}{*}{ Wilson's Score } & $\geq 5$ & 0 & 0 & & \\
\hline & $<5$ & $79(39.5 \%)$ & $121(60.5 \%)$ & & \\
\hline \multicolumn{6}{|c|}{ Table 3: Comparison of Two Groups by Airway Related Variables } \\
\hline
\end{tabular}

\begin{tabular}{|c|c|c|c|c|c|}
\hline \multicolumn{2}{|c|}{ Variables } & \multirow{2}{*}{$\begin{array}{c}\begin{array}{c}\text { Difficult } \\
\text { Intubation } \\
\text { (IDS>0) Number (\%) }\end{array} \\
16(72.7 \%)\end{array}$} & \multirow{2}{*}{$\begin{array}{c}\text { No } \\
\text { Difficulty } \\
\text { (IDS=0) Number (\%) }\end{array}$} & \multirow{3}{*}{$\begin{array}{c}\text { Odds } \\
\text { Ratio (CI) } \\
4.8 \\
(1.8-13)\end{array}$} & \multirow{3}{*}{$\begin{array}{c}\mathbf{P} \\
\text { value } \\
0.001\end{array}$} \\
\hline \multirow{2}{*}{ Duration } & $\geq 60$ Months & & & & \\
\hline & $<60$ Months & $63(35.4 \%)$ & $115(64.6 \%)$ & & \\
\hline \multirow{2}{*}{$\begin{array}{c}\text { Neck } \\
\text { Circumference }\end{array}$} & $\geq 35 \mathrm{~cm}$ & $42(53.2 \%)$ & $68(56.2 \%)$ & \multirow{2}{*}{$0.8(0.51 .5)$} & \multirow[b]{2}{*}{0.67} \\
\hline & $<35 \mathrm{~cm}$ & $37(46.8 \%)$ & $53(43.8 \%)$ & & \\
\hline \multirow{2}{*}{$\begin{array}{c}\text { Compressive } \\
\text { Symptoms } \\
\end{array}$} & Yes & $16(84.2 \%)$ & $3(15.8 \%)$ & \multirow{2}{*}{$\begin{array}{c}9.9 \\
(2.8-35.5) \\
\end{array}$} & \multirow[b]{2}{*}{0.001} \\
\hline & No & $63(34.8 \%)$ & $118(65.2 \%)$ & & \\
\hline \multirow{2}{*}{$\begin{array}{l}\text { Tracheal } \\
\text { Deviation }\end{array}$} & Yes & $25(80.6 \%)$ & $6(19.4 \%)$ & $\begin{array}{c}8.8 \\
(3.4-22.8)\end{array}$ & 0.001 \\
\hline & No & $54(32.0 \%)$ & $115(68.0 \%)$ & & \\
\hline \multirow{3}{*}{$\begin{array}{l}\text { Type of } \\
\text { Thyroid } \\
\text { Disease }\end{array}$} & $\begin{array}{c}\text { Ca } \\
\text { Thyroid }\end{array}$ & $1(8.3 \%)$ & $11(91.7 \%)$ & $\begin{array}{c}0.12 \\
(0.01-1.01)\end{array}$ & 0.02 \\
\hline & MNG & $62(58.5 \%)$ & $44(41.5 \%)$ & $\begin{array}{c}6.3 \\
(3.3-12.2)\end{array}$ & 0.001 \\
\hline & $\begin{array}{c}\text { Solitary } \\
\text { Nodule }\end{array}$ & $16(19.5 \%)$ & $66(80.5 \%)$ & $\begin{array}{c}0.2 \\
(0.1-0.4)\end{array}$ & 0.001 \\
\hline \multicolumn{6}{|c|}{ Table 4: Comparison of Two Groups by Thyroid Related Variables } \\
\hline
\end{tabular}




\begin{tabular}{|c|c|c|c|c|c|c|c|}
\hline Variables & B & S.E & Wald & df & Sig & $\begin{array}{l}\text { Exp } \\
\text { (B) }\end{array}$ & 95\% C.I \\
\hline Gender & .785 & .603 & 1.696 & 1 & .193 & 2.193 & $\begin{array}{lll}.673 & -- & .785\end{array}$ \\
\hline Age & -.204 & .229 & .792 & 1 & .373 & .816 & $\begin{array}{lll}512 & -- & -.204\end{array}$ \\
\hline $\begin{array}{l}\text { Thyromental } \\
\text { Distance }\end{array}$ & 83.136 & $7.006 \mathrm{E} 4$ & .000 & 1 & .999 & $1.275 \mathrm{E} 36$ & $.000 \quad--83.136$ \\
\hline Wilson's Score & 21.161 & $2.564 \mathrm{E} 4$ & .000 & 1 & .999 & $1.550 \mathrm{E} 9$ & $\begin{array}{lll}.000 & -- & 21.161\end{array}$ \\
\hline Mallampati Class & -.676 & .745 & .824 & 1 & .364 & .508 & $\begin{array}{lll}.118 & -- & -.676 \\
\end{array}$ \\
\hline Neck Circumference & -.038 & .353 & .012 & 1 & .914 & .963 & $\begin{array}{lll}482 & -- & -.038\end{array}$ \\
\hline $\begin{array}{l}\text { Atlanto-Occipital } \\
\text { Extension }\end{array}$ & -.756 & .942 & .644 & 1 & .422 & .469 & $.074 \quad--2.976$ \\
\hline Ca Thyroid & .666 & .649 & 1.054 & 1 & .304 & 1.947 & $.546--.666$ \\
\hline $\begin{array}{c}\text { Multi-Nodular } \\
\text { Goitre }\end{array}$ & -.724 & .377 & 3.682 & 1 & .055 & .458 & $\begin{array}{lll}.231 & -- & -.724\end{array}$ \\
\hline Solitary Nodule & .311 & .293 & 1.124 & 1 & .289 & 1.365 & $\begin{array}{lll}.768 & -- & 2.426 \\
\end{array}$ \\
\hline $\begin{array}{l}\text { Tracheal } \\
\text { Deviation }\end{array}$ & -1.184 & .682 & 3.009 & 1 & .083 & .306 & $\begin{array}{lll}.080 & -- & -1.184\end{array}$ \\
\hline $\begin{array}{l}\text { Compressive } \\
\text { Symptoms }\end{array}$ & .206 & .765 & .072 & 1 & .788 & 1.229 & $.274 \quad--.206$ \\
\hline
\end{tabular}

Study shows a higher prevalence of Thyroid disorders in female population $(90.5 \%)$ than the male $(9.5 \%)$. In the study population $39.5 \%$ have difficulty in intubation (IDS $>0$ ), of which $7 \%$ had severe intubation difficulty (IDS $>5$ ). On univariate analysis, male gender (OR 16.3, CI 3.6-72), thyroid swelling with tracheal deviation (OR 8.8, CI 3.4-22.8), swelling with compressive symptoms (OR 9.0, CI 2.8-35.5), the duration of the swelling $>5$ yrs. (OR 4.8, CI 1.8-13) and type of the swelling (for MNG, OR 6.3, CI 3.3-12.2 when compared to solitary nodule) were identified as potential thyroid related risk factors associated with difficult intubation. Logistic regression showed that male gender, carcinoma thyroid and thyroid swelling with compressive symptoms were the three independent variables associated with difficult intubation.

\section{DISCUSSION}

Two hundred patients posted for elective thyroid surgery who fulfilled the inclusion criteria were evaluated, of which $39.5 \%$ (79 out of 200) had mild or severe difficulty in intubation (IDS >0). Seven percent (14 of 200) of the same had moderate-to-severe difficulty (IDS >5). This is comparable with that of general population and found that thyroid swelling as such does not increase the incidence of difficult intubation. ${ }^{6,7,15]}$

In the study by Bouaggad et al[6] using the IDS showed that in a population of 320 patients undergoing thyroidectomy for goitre, the incidence of moderate-tosevere intubation difficulty was only $5.3 \%$, but mild difficulty for intubation was found in $57.8 \%$ of cases. In another study by Amathieu et al[7] of the 324 patients undergoing thyroidectomy, $11.1 \%$ had moderate-to-severe difficulty (IDS $>5$ ) during tracheal intubation. Another prospective study of 199 patients for thyroidectomy by Voyagis et al,[15] the incidence of difficult intubation was $8.5 \%$.

The study showed that even though the prevalence of goitre is low in male population, they showed more intubation difficulty (89.5\%) than females $(34.3 \%)$, which was also found to be statistically significant (OR 16.3, CI=3.672). In a study, Kalezic Nevena K et al[16] had described that incidence of difficult intubation in thyroid gland surgery is twice more in men than in women.

of the airway related variables studied, only atlanto-axial extension has significant association with difficult intubation. But this variable did not have significant association on multivariate analysis. The influence of mouth opening could not be assessed in relation to intubation difficulty since all patients had mouth opening $>2$ finger-breadth $(3 \mathrm{~cm})$ in the study. Mallampati class and Thyromental distance did not have any significant association with difficult intubation in the present study. Wilson's score again showed no association, since none among the population had a score $>5$. This warrants the need for further study with more sample size.

Of the thyroid related variables, swellings with duration $>5$ yrs. showed statistically significant association (OR 4.8, $\mathrm{CI}=1.8-13$ ) with difficult intubation (With $72.7 \%$ showing difficulty). Malhotra et al[17] in their literature had described the importance of the duration of goitre associated with intubation difficulty.

In our study, we have taken neck circumference as a surrogate measure for the size of thyroid swelling; $53.2 \%$ of patients with mild-to-severe intubation difficulty had neck circumference more than or equal to $35 \mathrm{cms}$, though it was not found to be statistically significant (OR $0.8, \mathrm{CI}=0.5-1.5$ ). Eight patients with severe intubation difficulty (57.1\%), had neck circumference more than or equal to $35 \mathrm{cms}$. In the study by Gonzalez et al,[18] neck circumference $>43 \mathrm{~cm}$ at the laryngeal cartilage level has been described for prediction of difficult intubation.

In the study by Bouaggad et al[6] using the IDS found an increase in difficulty of intubation only when malignant thyroid was present. Our study also have significant association between carcinoma thyroid and difficult intubation (OR 6.3, $\mathrm{CI}=3.3-12.2$ ). In a study of 2000 patients by Kalezic $\mathrm{N}$ et al,[16] they found an association between MNG and difficult intubation.

Many articles[19-21] have been published suggesting that goitre when accompanied by tracheal compression constitutes an aggravating factor for difficult airway, but no 
resistance was encountered in passage of the endotracheal tube through the compressed or narrowed portion of the trachea. Our study have significant association for both compressive symptoms (OR 9.9, $\mathrm{CI}=2.8-35.5$ ) and tracheal deviation (OR 8.8, $\mathrm{CI}=3.4-22.8$ ) with difficult intubation.

Even though univariate analysis showed significant association with male gender, tracheal deviation, compressive symptoms, duration of swelling and type of swelling, logistic regression showed that male gender, malignant thyroid and swelling with compressive symptoms are three independent variables associated with difficult intubation.

\section{CONCLUSION}

\section{The Major Findings of this Study are}

(a) Easy tracheal intubation is possible in $60.5 \%$ of patients with thyroid swelling. Of the remaining $39.5 \%$, $7 \%$ was associated with moderate-to-severe difficulty. This is comparable with that of general population indicating the fact that thyroid swelling as such does not increase the risk of difficult intubation.

(b) Male gender, carcinoma thyroid and thyroid swelling with compressive symptoms were independent risk factors for difficult intubation.

(c) The size of the thyroid swelling as such was not associated with a high risk of difficult Intubation.

\section{REFERENCES}

1. Bartolek D, Frick A. Huge multinodular goitre with midtrachea obstruction: indication for fiberoptic intubation. Acta Clin Croat 2012;51(3):493-8.

2. Mallampati SR, Gatt SP, Gugino LD, et al. A clinical sign to predict difficult tracheal intubation: a prospective study. Can Anaesth Soc J 1985;32(4):429-34.

3. Wilson ME, Spiegelhalter D, Robertson JA, et al. Predicting difficult intubation. $\mathrm{Br} \quad \mathrm{J}$ Anaesth 1988;61(2):211-6.

4. Gupta S, Sharma KRR, Jain D. Airway assessment: predictors of difficult airway. Indian J Anaesth 2005;49(4):257-62.

5. Reed AP. Evaluation and recognition of the difficult airway. In: Carin A, Hagberg, eds. Benumof's airway management. 2nd edn. Philadelphia: Mosby 2006:223-6.

6. Bouaggad A, Nejmi SE, Bouderka MA, et al. Prediction of difficult tracheal intubation in thyroid surgery. Anesth Analg 2004;99(2):603-6.
7. Amathieu R, Smail N, Catineau J, et al. Difficult intubation in thyroid surgery: myth or reality? Anesth Analg 2006;103(4):965-8.

8. Kalezic N, Milosavljevic R, Paunović I, et al. The incidence of difficult intubation in 2000 patients undergoing thyroid surgery - a single center experience. Vojnosanit Pregl 2009;66(5):377-82.

9. Samsoon GL, Young JR. Difficult tracheal intubation: a retrospective study. Anaesthesia 1987;42(5):487-90.

10. Tham EJ, Gilldersleve CD, Sanders LD, et al. Effects of posture, phonation and observer on Mallampati classification. Br J Anaesth 1992;68(1):32-8.

11. Finucane, Brendan, Tsui, et al. Principles of airway management. Evaluation of the airway. $4^{\text {th }}$ edn. Verlag New York, Springer 2011:34-46.

12. Chou HC, Wu TL. Mandibulohyoid distance in difficult laryngoscopy. Br J Anaesth 1993;71(3):335-9.

13. Chou HC, Wu TL. Thyromental distance: shouldn't we redefine its role in prediction of difficult laryngoscopy? Acta Anaesthesiology Scand 1998;42(1):136-7.

14. Cormack RS, Lehane J. Difficult tracheal intubation in obstetrics. Anaesthesia 1984;39(11):1105-11.

15. Voyagis GS, Kyriakos KP. The effect of goitre on endotracheal intubation. Anesth Analg 1997;84(3): 611-2.

16. Nevena KK, Milena K, Ivan PR, et al. Incidence of difficult intubation in thyroid gland surgery. Archive of Oncology 2003;11(3):187-7.

17. Malhotra S, Sodhi V. Anaesthesia for thyroid and parathyroid surgery. Continuing Education in Anaesthesia, Crit Care Pain 2007;7(2):55-8.

18. Gonzalez H, Minville V, Delanoue K, et al. The importance of increased neck circumference to intubation difficulties in obese patients. Anesth Analg 2008;106(4):1132-6.

19. Ghai A, Hooda S, Wadhera R, et al. Gross tracheal deviation: airway challenges and concerns - two case reports. Acta Anaesth Belg 2011;62(4):203-6.

20. Souza JW, Williams JT, Ayoub MM, et al. Bilateral recurrent nerve paralysis associated with multinodular substernal goiter: a case report. Am Surg 1999;65(5):456-9.

21. Shaha AR. Airway management in anaplastic thyroid carcinoma. Laryngoscope 2008;118(7):1195-8. 